\title{
In patients with early prostate cancer, is surgery better than watchful waiting?
}

Bill-Axelson A, Holmberg L, Ruutu M, Haggman M, Andersson SO, Bratell S, et al; Scandinavian Prostate Cancer Group Study No. 4. Radical prostatectomy versus watchful waiting in early prostate cancer. N Engl J Med 2005;352(19):1977-84.

Background: Two strategies to manage early prostate cancer are in common use: radical prostatectomy (RP) and watchful waiting (WW). Which of them results in better long-term survival has yet to be shown.

Design: A randomized, multicentre trial was conducted by the Scandinavian Prostate Cancer Group, beginning in 1989. A total of 695 patients no older than 75 years who had clinical stage T1b, T1c or T2 prostate cancer that was well or moderately differentiated, were fit for surgery and had an estimated life expectancy of at least 10 more years were randomly assigned to the RP group (347 men) or to the WW group (348 men). Death due to prostate cancer was the end point of primary interest; metastasis-free survival, local progression and overall mortality were secondary end points. Initial results were reported in 2002 after a median follow-up of 6.2 years; the current article describes outcomes $\vec{n}$ after 3 more years of follow-up.

Results: After a median followup of 8.2 years, lower rates of adverse outcomes were associated with RP (Table 1): risk for disease-specific mortality was reduced by $44 \%$ relative to the

Table 1: Results at 5 and 10 years of follow-up for patients with early prostate cancer treated with radical prostatectomy (RP) or watchful waiting (WW), in \%

\begin{tabular}{lrrrrrrr}
\hline & \multicolumn{3}{c}{ At $5 \mathrm{yr}$} & & \multicolumn{3}{c}{ At $10 \mathrm{yr}$} \\
\cline { 2 - 3 } \cline { 7 - 8 } Outcome & RP & WW & & RP & WW & $p$ value \\
\hline Disease-specific mortality & 2.3 & 4.3 & & 9.6 & 14.9 & 0.01 \\
Distant metastasis & 8.1 & 9.8 & & 15.2 & 25.4 & 0.004 \\
Local progression & 8.1 & 27.2 & & 19.2 & 44.3 & $<0.001$ \\
Overall mortality & 7.8 & 9.8 & & 27.0 & 32.0 & 0.04 \\
\hline
\end{tabular}

WW group; distant metastases, by $40 \%$; local progression, by $67 \%$; and overall mortality, by $26 \%$. When compared with the findings at 5 years of follow-up, outcome differences between RP and $W W$ treatment continued to widen for all 4 end points. In prespecified subgroup analyses, men aged 65 years or older showed no significant decrease in disease-specific mortality after RP; the benefit was unaffected by Gleason score or prostate-specific antigen level at entry. Long-term complications from RP were not reported.

Commentary: This article reports the results after an extended follow-up period of a seminal clinical trial in early prostate cancer. ${ }^{1}$ The original study results revealed statistically significant reductions in disease-specific mortality and metastases with surgery, but no effect on overall survival. With longer follow-up, the current results provide high-quality evidence in favour of surgical therapy for early prostate cancer.

When we consider how the results of this trial might affect the management of a man with newly diagnosed early prostate cancer, 3 issues arise. First, most men in this trial had palpable (stage T2) disease and mean prostate-specific antigen levels of $12-13 \mu \mathrm{g} / \mathrm{L}$. In comparison, most men diagnosed in North America (with its much higher penetration of screening) have impalpable (T1c) disease with lower levels of prostate-specific antigen. Thus, whether the benefits found in the study population would be equally impressive in men with even earlier disease is unknown.

Second, this study excluded men with high-risk prostate cancer, who generally have stage T2 c tumours and Gleason scores of 8 to 10 , and are much more likely to die from prostate cancer within 5 years of diagnosis. ${ }^{2}$ Although such men are generally treated aggressively, with combinations of surgery or radiation therapy plus adjuvant hormonal therapy, there is no evidence from randomized trials supporting the superiority of this approach over WW.

Third, whether similarly impressive benefits in end-point reduction would be seen with radiation therapy (either external beam or brachytherapy) is also unknown, even though in Ontario more men receive radiation therapy than surgery for the treatment of prostate cancer. ${ }^{3}$

Practice implications: This high-quality trial provides further evidence of benefit from RP compared with WW in reasonably healthy men up to age 75 with early prostate cancer. Whether similar benefits can be found with radiation therapy or in men with more aggressive disease remains to be established.

\section{Shabbir M.H. Alibhai}

Sven Gogov

Division of General Internal

Medicine and Clinical Epidemiology University Health Network

Toronto, Ont.

\section{References}

1. Holmberg L, Bill-Axelson A, Helgesen F, Salo JO, Folmerz P, Haggman M, et al; Scandinavian Prostatic Cancer Group Study Number 4. A randomized trial comparing radical prostatectomy with watchful waiting in early prostate cancer. N Engl 7 Med 2002; 347(11):781-9.

2. Albertsen PC, Hanley JA, Gleason DF, Barry MJ. Competing risk analysis of men aged 55 to 74 years at diagnosis managed conservatively for clinically localized prostate cancer. $7 A M A$ 1998;280(11):975-80.

3. Alibhai SM, Krahn MD, Cohen MM, Fleshner NE, Tomlinson G, Naglie $\mathrm{G}$. Is there age bias in the treatment of localized prostate carcinoma? Cancer 2004;100(1):72-81. 